\title{
Supporting Technology at GRC to Mitigate Risk as Stirling Power Conversion Transitions to Flight
}

\author{
Jeffrey G. Schreiber ${ }^{1}$, Lanny G. Thieme ${ }^{2}$ and Wayne A. Wong ${ }^{3}$ \\ NASA Glenn Research Center at Lewis Field, Cleveland, Ohio, 44135
}

\begin{abstract}
Stirling power conversion technology has been reaching more advanced levels of maturity during its development for space power applications. The current effort is in support of the Advanced Stirling Radioisotope Generator (ASRG), which is being developed by the U.S. Department of Energy (DOE), Lockheed Martin Space Systems Company (LMSSC), Sunpower Inc., and the NASA Glenn Research Center (GRC). This generator would use two high-efficiency Advanced Stirling Convertors (ASCs) to convert thermal energy from a radioisotope heat source into electricity. Of paramount importance is the reliability of the power system and as a part of this, the Stirling power convertors. GRC has established a supporting technology effort with tasks in the areas of reliability, convertor testing, high-temperature materials, structures, advanced analysis, organics, and permanent magnets. The project utilizes the matrix system at GRC to make use of resident experts in each of the aforementioned fields. Each task is intended to reduce risk and enhance reliability of the convertor as this technology transitions toward flight status. This paper will provide an overview of each task, outline the recent efforts and accomplishments, and show how they mitigate risk and impact the reliability of the ASC's and ultimately, the ASRG.
\end{abstract}

\section{Nomenclature}

$\begin{array}{ll}\text { ASC } & =\text { Advanced Stirling Convertor } \\ \text { ASRG } & =\text { Advanced Stirling Radioisotope Generator } \\ \text { CFD } & =\text { computational fluid dynamic } \\ C T P C & =\text { Component Technology Power Convertor } \\ \text { DOE } & =\text { Department of Energy } \\ \text { EU } & =\text { Engineering Unit } \\ F T A & =\text { fault tree analysis } \\ \text { GPHS } & =\text { General Purpose Heat Source } \\ \text { GRC } & =\text { Glenn Research Center } \\ H I P & =\text { hot isostatic press } \\ \text { LMSSC } & =\text { Lockheed Martin Space Systems Company } \\ N R A & =\text { NASA Research Announcement } \\ \text { QA } & =\text { Quality Assurance } \\ R G A & =\text { residual gas analyzer } \\ S B I R & =\text { Small Business Innovative Research } \\ S P D E & =\text { Space Power Demonstrator Engine } \\ T D C & =\text { Technology Demonstration Convertor } \\ W & =\text { watts }\end{array}$

\section{Introduction}

7 he NASA Glenn Research Center (GRC) has been involved in the development of many advanced energy 1 conversion technologies for a wide range of applications, including free-piston Stirling power conversion

\footnotetext{
${ }^{1}$ Team Lead, Thermal Energy Conversion Branch, 21000 Brookpark Road/Mail Stop 301-2, AIAA Senior Member.

${ }^{2}$ Mechanical Engineer, Thermal Energy Conversion Branch, 21000 Brookpark Road/Mail Stop 301-2.

${ }^{3}$ Project Manager, Thermal Energy Conversion Branch, 21000 Brookpark Road/Mail Stop 301-2.
} 
technology over much of the past 30 years. At times, the effort has focused on applications other than space power, such as residential heat activated heat pumps and distributed dish solar energy conversion for use with the national power grid. During the late 1970's and the first half of the 1980's, this activity was carried out in parallel with the development of kinematic Stirling engine technology intended for applications such the automotive market and military generator sets. Some of the key technologies exist in both the kinematic and the free-piston types of Stirlings; however, there are some technologies that are unique to one type of Stirling. The shared technologies include thermodynamic cycle analysis, heat exchangers, high temperature materials, and life and reliability analysis. Some Stirling technologies unique to the free-piston type are the linear alternators, modeling of non-linear resonant dynamics, and free-piston controllers.

The first free-piston Stirling power conversion effort at GRC that was directed at space power systems was under the SP-100 project. This joint project involved the Department of Energy (DOE), the Department of Defense, and NASA. The baseline system featured a reactor as the heat source with thermoelectrics to convert the heat to electric power. Following the successful operation of the Space Power Demonstrator Engine (SPDE), Stirling power conversion was chosen as the backup power conversion option for SP-100. The SPDE produced about $25 \mathrm{kWe}$ output from two pistons in a configuration that resulted in a dynamic balanced power conversion system. ${ }^{1}$ This led to the subsequent development of the Component Technology Power Convertor (CTPC), which produced about 13 $\mathrm{kWe}$ from a single piston as it was decided to build only half of what could be a pair of pistons for dynamic balance. Both the SDPE and the CTPC were hermetically sealed and achieved non-contacting operation of the moving parts through the use of gas bearings to have the capability for long-life. System optimization resulted in a temperature ratio of the Stirling power convertor of 2.0, which presented a challenge when trying to maintain the high efficiency. This project demonstrated some of the most critical technologies for life and reliability in dynamically balanced operation, non-contacting operation, in a design that could be hermetically sealed., ${ }^{2,3}$

Studies began at GRC in 1989 to evaluate free-piston Stirling power conversion as an option for use with a radioisotope heat source. ${ }^{4,5}$ The potential applications of these initial studies included unmanned deep space probes and planetary surface exploration missions, with some of these studies looking at human tended rovers. ${ }^{6}$ The design challenges were somewhat different from the SP-100 application in that the power levels were in the multi-hundred watt range, making the low-mass goals a challenge, and the temperature ratio was slightly higher at about 2.4. Several efforts followed through Small Business Innovative Research (SBIR) contracts, the first of which produced the design of a multi-hundred watt Stirling technology demonstrator for space. ${ }^{7}$ Following numerous studies by the Government, DOE issued three contracts in August 2000 for the conceptual design of a generator under the Stirling Radioisotope Generator project. Lockheed Martin Space Systems Company (LMSSC) was ultimately selected as the system integration contractor and the formal design of the generator began in May 2002. This project evolved over time as new technologies became available, and is now called the Advanced Stirling Radioisotope Generator (ASRG) project.

Figure 1 shows the ASRG Engineering Unit (EU) with part of the outer housing removed to show the internal components. This is a non-nuclear generator that uses electrically heated simulators of the General Purpose Heat Source (GPHS) modules and is used to validate the engineering of the generator. The ASRG-EU was assembled in 2007 and underwent system level testing at LMSSC in 2008. The ASRG uses two Advanced Stirling Convertors (ASC) inside a beryllium enclosure that acts as structure, radiator, and micrometeoroid shield. The convertors are aligned in the generator housing and synchronized to provide dynamic balance. Unlike the designs of the 1990's, the hot ends of the two Stirling convertors are located away from one another, rather than in one central heated zone. This configuration eliminates one potential form of fault propagation since an over-temperature condition of one heat source cannot affect the operation of the Stirling convertor at the other end of the generator.

Sunpower Inc., of Athens OH developed the ASC under contract to NASA. The contract was awarded as a result of the 2002 NASA Research Announcement (NRA) 02-OSS-01 entitled "Radioisotope Power Conversion

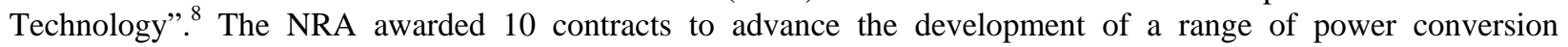
technologies with the goal of providing higher conversion efficiency and specific power than the GPHS Radioisotope Thermoelectric Generator. Although the ASC is a product of the NRA contract, the basis for the ASC can be traced back to an SBIR contract awarded to Sunpower to develop the EE-35 Stirling convertor. ${ }^{9}$ The EE-35 Stirling convertor was sized to accept half of the heat generated by one GPHS module; therefore, a single heat source located between two EE-35 convertors would comprise a dynamically balanced system. The ASC design began as a higher power version of the EE-35, sized to accept all of the heat generated by one GPHS module, and has undergone much refinement as it approaches a potential flight status. 
LMSSC under contract to DOE holds responsibility for development of the generator, however, during the EU phase, the Stirling convertors were supplied as Government Furnished Equipment by the GRC/Sunpower team per the requirements developed by LMSSC. Figure 2 shows the convertors for the ASRG-EU, designated as ASC-Es. This organization of the project during the EU phase seeks to enhance the maturation process of the ASC design and the capabilities of the supplier, all for the purpose of minimizing

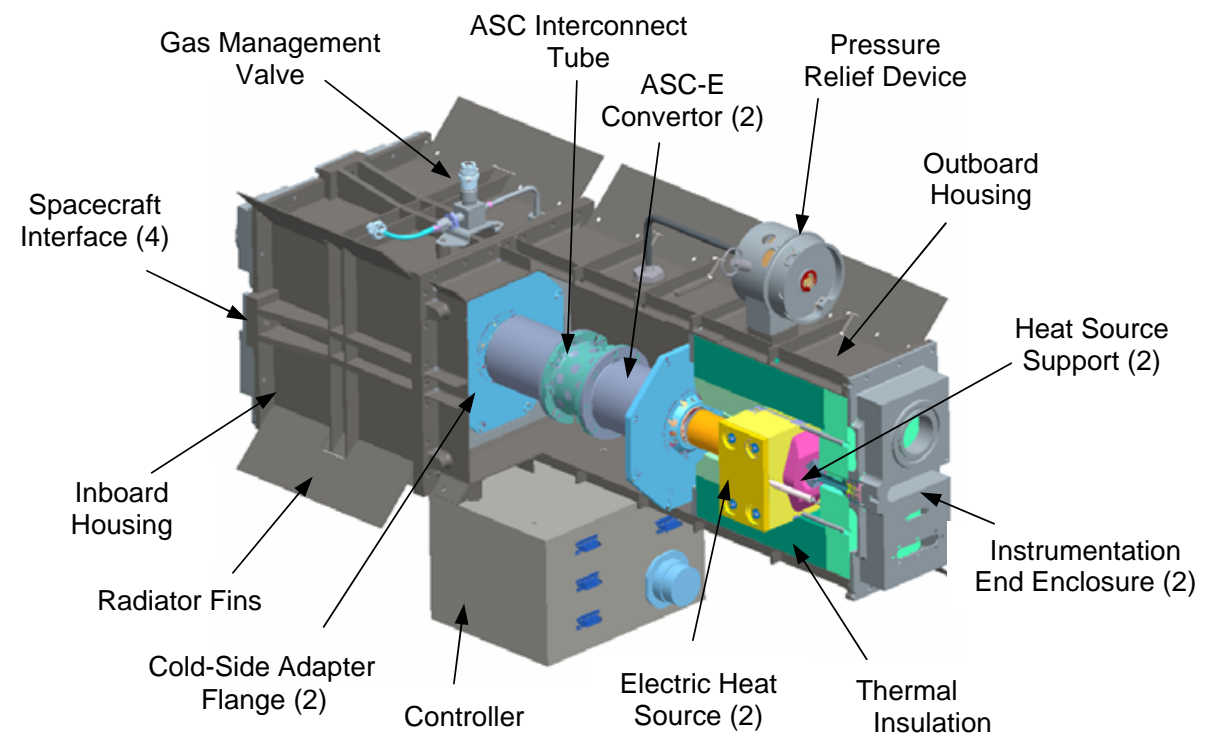

Figure 1. Advanced Stirling Radioisotope Generator Engineering Unit. Image of the generator with a section of the housing removed to show the internal components. The controller is a developmental prototype for the engineering unit and is not representative of flight controller.

risk as a potential flight opportunity approaches. The design of the ASC needs to evolve somewhat during this process since the NRA effort did not include any aspects of system integration. Furthermore, the ASC needs to evolve to integrate into an existing baseline system design as the generator design existed prior to the convertor. ${ }^{10}$ As currently planned, the next build, designated the ASC-E2, will change the heater head material from Inconel 718 to MarM-247. This will be followed by the ASC-E3 convertor. Changes between the E2 and E3 design should focus on refining the manufacturing processes. This all is in preparation for the next build being for an ASRG Qualification Unit.

The GRC contribution to the development of the ASC comes in project management and also in supporting technology. Resident experts at GRC are brought into the project through the matrix system and provide support in areas such as reliability, convertor testing, high-temperature materials, structures, advanced analysis, organics, and permanent magnets. The purpose of each of these tasks is to mitigate risk and enhance the reliability of the ASC. These tasks may result in some improvements in performance or reduction in mass of the ASC; however, they are neither the intent nor a deciding factor. This paper will describe some of the activities and key accomplishments in the GRC

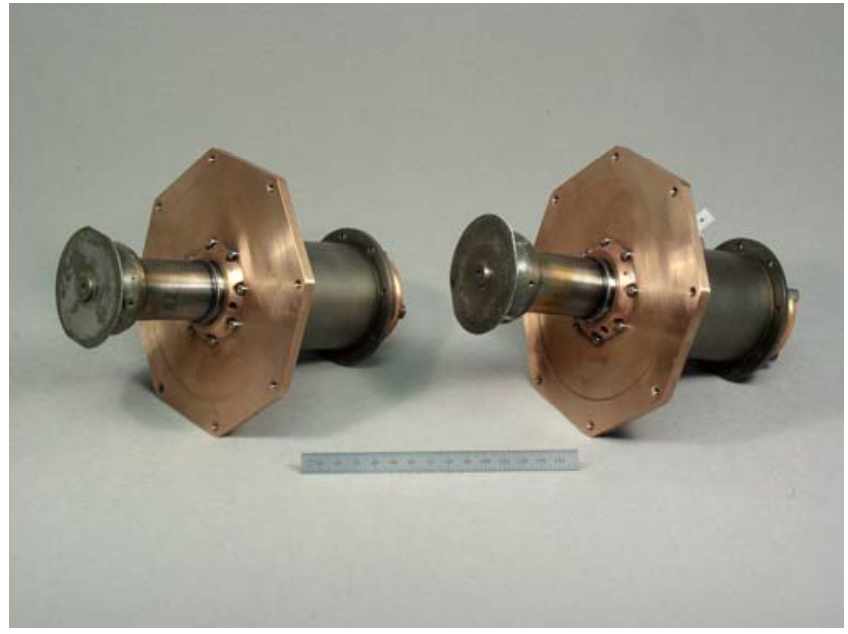

Figure 2. A pair of ASC-E Stirling convertors. Two convertors prior to delivery to LMSSC for integration into the ASRG-EU generator, with heater head to the left and pressure vessel to the right. supporting technology effort.

\section{Supporting Technology}

As mentioned previously, the GRC supporting technology effort consists of tasks in reliability, convertor testing, high-temperature materials, structures, advanced analysis, organics, and permanent magnets. In prior years, the GRC technology portfolio contained elements of advanced technology, distinct from and complementary to the more 
near-term technology. Some of the features of the ASC evolved from the advanced technology effort, such as the heater head. At this point, however, all of the tasks focus on the current ASC design, and more specifically, risk mitigation for the ASC design. This often takes the form of refining production process to reduce or eliminate variability, augmenting databases of materials or operational characteristics, advanced analysis of structures and fluid dynamics.

\section{A. Reliability}

During the initial development phase of the ASC under the NRA project, Sunpower maintained a task to address reliability with GRC providing some support based in experience from previous projects. As the emphasis of this project has shifted to system integration, LMSSC has taken on the leadership for overall reliability, consistent with their role as the system integration contractor responsible for reliability of the integrated generator. ${ }^{12}$ GRC and Sunpower continue to play key roles in the efforts coordinated through the ASRG Reliability Working Group. The intent is to mitigate risk and maximize reliability in meeting the 17 year life requirement for the ASRG. GRC reliability engineers had previously developed a Fault Tree Analysis (FTA) of the ASC, which provided one of the sources of information as LMSSC developed the FTA of the ASRG. The project also developed Failure Mode, Effects, and Criticality Analyses (FMECA) of the major subsystems of the generator which is once again, led by LMSSC. A team that included expertise from Stirling researchers and reliability engineers from GRC and Sunpower developed the ASC FMECA.

Probabilistic analysis of components and subsystems provides one source of input to the system-level reliability analysis. This technique has a long heritage GRC ${ }^{11}$ and has been used routinely for a range of aeronautics and space applications. Reliability of a component or subsystem can be quantified by developing a model and representing all input parameters as variables, with each one having a statistical distribution based on the nature of the parameter. For example, dimensions will vary over the range of tolerances allowed during the manufacturing process, while material properties will have some variability based on the level of control in the manufacturing process. This technique has proven itself to be valuable when there is insufficient data to calculate reliability, when the designers need to know which parameters influence the reliability the most, and when design options are evaluated during the design process. The most common component that has been assessed and guided by probabilistic analysis is the heater head, which will be addressed in the section on structures.

GRC provided support in the area of flight quality mechanical design to enhance reliability. These practices differ somewhat from those used to design a high quality product for commercial applications. The support has generally been in the areas of structural analysis, the design documentation including drawings and procedures, and in the selection and evaluation of fasteners. This last area proved to be challenging as all of the fasteners in the ASCs are smaller than what is generally considered to be a structural fastener. This effort used detailed analysis combined with tests to characterize the candidate fasteners, and showed that all fasteners can meet the margins required for flight.

Support has also been provided by GRC in the area of Quality Assurance (QA). Under the ASC project, Sunpower developed a QA system that when fully implemented, should support flight development under the DOE standards commonly used for radioisotope systems. Much of the ASC hardware produced to date, including the ASC-Es for the EU generator, utilized a partial QA system. However, Sunpower recently completed their QA system, for use in all future builds.

The purpose of the reliability effort is to identify areas of risk, quantify risk and failure rates wherever possible, identify areas where risk might be mitigated, and develop a database to verify life and reliability of the convertor. Tasks in other areas are intended to support these goals.

\section{B. Convertor Testing}

All free-piston Stirling convertors that NASA has considered for use in a space power system have been based on long-life technologies and design principles; that is, they have non-contacting operation of the moving components and have robust margins in all components that may potentially be subjected to creep or fatigue. The dilemma with such devices is that while accelerated life testing may be able to performed on individual components, it is not possible with the complete Stirling convertor. The parameter that may be used to accelerate the life of one component may be unacceptable to another component. A similar situation exists with the long-life space flight cryocoolers. GRC has been testing candidate Stirling convertors for radioisotope systems since 2000, and has had Stirling convertors on extended operation since 2003. The term extended operation is used to describe continuous operation, 24 hours per day, with shutdowns only as required by facility issues. To date, over 200,000 hours of operation has been accumulated among 14 convertors that have undergone extended operating testing. 
Most of the convertors used in extended operation tests have been hermetically sealed with the exception of the fill tube. GRC developed a system that extracts a small amount of the helium working fluid from the fill tube and sends it to a Residual Gas Analyzer (RGA). The RGA analyzes the purity of the helium and can detect any outgassing of components inside the convertor, or if any chemical reactions may occur. Early in the extended operation tests, it was felt that there would be more value in analyzing the purity of the helium working fluid as a means of early detection of improper operation or potential degradation. This was based in part on the organics used in the convertor as adhesives, insulators, and as coating on the moving components. While this method has been shown to be able to detect very small quantities of contaminants, there has been no evidence in these tests of unexpected outgassing or reactions. The system detected outside atmosphere permeating through polymer o-rings into the convertors, and the release of gasses trapped in blind holes during manufacturing, neither of which pose a concern for flight hardware.

Six units of an early design known as the Technology Demonstration Convertor (TDC) have undergone extended operation test at GRC. The TDC was developed by Infinia Corporation, previously known as the Stirling Technology Company of Kennewick, WA. The TDC was sized similar to the ASC and was designed to use the heat from one GPHS module. The earliest build, listed at TDCs \#5 \& \#6 operated for slightly more than 10,000 hours in a thermal vacuum facility simulating operation in space. They were integrated with a heat source that simulated the GPHS module, and radiator panel that simulated the housing of the ASRG. The test was terminated when the vacuum facility was needed for another test article. TDCs \#13 and \#14 have accumulated over 38,000 hours and continue to operate with no change in performance. Similar units known as TDCs \#15 and \#16 have accumulated over 24,000 hours of operation. While these convertors are not considered for use in the ASRG, they do contain some of the same organic compounds as are used in the ASCs, and therefore continue under extended operation to help build the database of long-term operation.

There have been five pairs of ASCs operated under extended operation at GRC, accumulating a total of over 45,000 hours. The ASCs that have been tested have varying degrees of QA as they were built with the intention of exercising elements of the QA system. The NRA project developed the ASC-1, which was the first convertor to use a MarM-247 heater head rather than Inconel 718 that had been used on the TDCs. The designation ASC-0 was developed to describe an ASC-1, with an Inconel 718 heater head, indicating that it had earlier technology than used in the ASC-1s. Four ASC-0s were built based on quality shop practice, and essentially none of the emerging flight QA system being applied. ASC-0 \#1 and \#2 were delivered to GRC in 2006 and have operated in thermal vacuum for over 11,000 hours. Figure 3 shows the test hardware for thermal vacuum operation. Some change in performance has been noted on one convertor, however there are reasons to believe that it may be due to instrumentation error and will remain under investigation. ASC-0 \#3 and \#4 were delivered to GRC in 2007 and have been operating in air for over 7,000 hours with steady

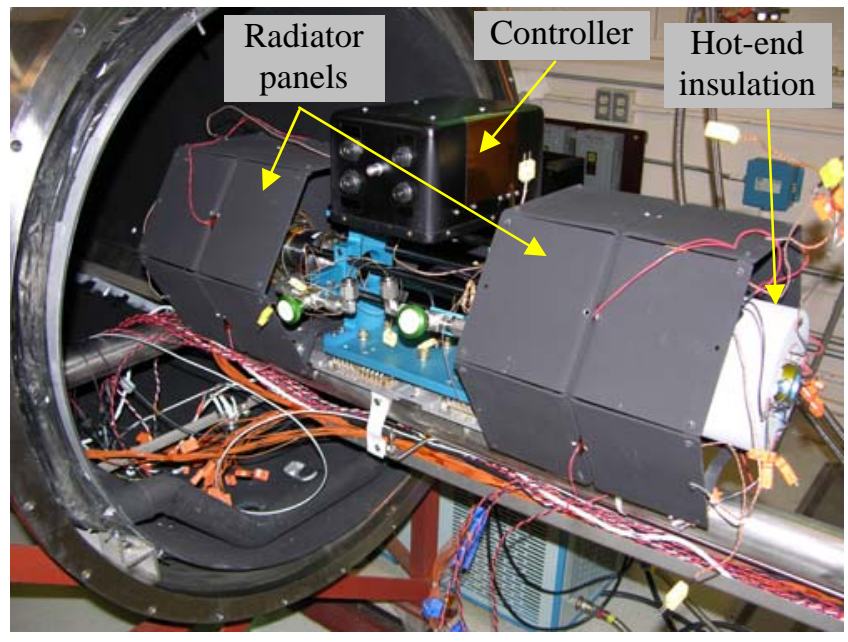

Figure 3. ASC-0 \#1 and \#2 in thermal vacuum test configuration. The convertors are located inside the radiator panels, with the controller mounted on top in the center. performance.

The ASC-1HS \#1 and \#2 convertors were delivered to GRC in 2007 and have been operated for approximately 2,400 hours. These convertors were designated as 1HS since they are similar to the research convertors of the NRA project known as ASC-1 having the MarM-247 heater heads, however the research ASC-1 convertors were not hermetically sealed. The "HS" designation for this pair indicates that they are hermetically sealed. The operating time on these convertors has been limited for multiple reasons. First, after being received at GRC, they underwent detailed profile measurement of the heater heads for creep characterization after many thousands of hours of operation. They were then instrumented with fine thermocouples to gain detailed data on heater head wall temperature profiles in support of heater head life analysis. With the Mar-M-247 heater heads, the desire was to operate near the $850^{\circ} \mathrm{C}$ design temperature, however, operating the electric heaters at high temperatures in air has proven to be troublesome. Lastly, there have been small anomalies in the otherwise steady-state operation. The anomalies appear as sporadic increases in power output of one to two watts (W), with a rise time of a few minutes, 
followed by a return to nominal operation that takes on the order of 10 minutes. The root cause of the anomalies has not bee found and remains under investigation, limiting the operational hours.

The ASC-1 \#3 and \#4 convertors were operated for approximately 2,000 hours. These convertors were a product of the NRA technology development project and, although they contained all of the key internal design features required for long-term operation, they were built with nine o-rings each on the pressure boundary. These convertors were intended to research the performance of the design features needed for long-life operation, however, this build of hardware was not intended for long-term operation. It was found that leakage of helium working fluid from the convertor, and permeation of outside air into the convertors made extended operation a challenge. The convertors are currently not operating in extended operation and are being used for focused tests.

The purpose of this task is to validate the key technologies by establishing a database of long-term operation. This includes all technologies integrated into a Stirling convertor, simulating operation in an integrated generator where possible.

\section{High-Temperature Materials}

High-temperature material tasks in the ASC development have covered numerous areas, each one trying to minimize risk and ensure repeatability and high reliability over the design life of the convertor. The tasks covered the areas of regenerator fabrication, MarM-247 material processing, heater head material creep tests, heater head permeation tests, and evaluation of joining techniques.

The regenerator is a heat exchanger made from a high-porosity, random fiber oxidation-resistant material. The material goes through steps of sintering, cutting, and cleaning to ensure that no fibers can come lose during operation. The techniques for producing high-reliability regenerators have been developed and demonstrated in convertor testing, and the technology has been transferred to Sunpower. A final test to ensure that the regenerator does not change shape or shrink over long periods of time. Past regenerators have not exhibited this problem.

A substantial database existed to support heater head design and life analysis when using Inconel 718 as the baseline heater head material. The much higher temperature capability prompted the change to MarM-247, and the margin that it provided when considering the uncertainty in operating temperature. Initially, it was felt that a MarM247 heater head operating at $850^{\circ} \mathrm{C}$ would have more margin, i.e., be less sensitive to over temperature, than Inconel 718 operating at $650{ }^{\circ} \mathrm{C}$. The change to MarM-247 significantly reduced the data available with respect to the required 17-year life, and introduced additional issues as this is a cast alloy rather than a wrought alloy. Initial characterization was through uniaxial creep testing with three grain sizes to determine if grain size would affect creep characteristics as it had with Inconel 718. One of the primary drivers with Inconel 718 was the existence of approximately 20 grains through the thinnest part of the heater head wall, however this same issue has not been found with MarM-247. Nonetheless, an optimal grain size for the ASRG application has been determined and all future creep testing will make use of this ASRG "spec" material. Controlling parameters associated with the casting process produces the desired grain size, and as a part of producing this material, it is also common practice to Hot Isostatic Press (HIP) the material to eliminate casting voids. This replaces processes that work the less strong wrought materials to eliminate their voids. HIPping parameters have been studied on samples with known voids, and samples with machined-in voids to validate the process and ensure reliability. In the future multiple samples will undergo creep testing at the same conditions to characterize the probabilistic distribution of material properties to support heater head life analysis.

GRC developed a test rig to characterize permeation of the helium working fluid through a heater head. This does not test for leakage, rather, it characterizes permeation through a heater head that has no voids in the pressure boundary. The concern is that at high operating temperature, some relatively small amount of helium may permeate through the heater head. For the IN718 heater head, analysis determined that the loss of helium over a 14-year mission resulted in an immeasurable change in Stirling convertor performance. For this test, the MarM-247 heater head was brazed to a stainless steel plug that allows pressurization of the internal volume of the head with helium. The test fixture places the heater head into an evacuated cavity with an RGA that is used to detect the presence of helium in the cavity. The system has been verified by a calibrated leak source of being capable of detecting a helium leak rate that is equivalent to a loss of less than $0.1 \%$ of the helium over the 17 -year life. Furthermore, given the diffusivity and solubility for this system, the tests do not need to be run for the design life to verify the permeation rate and relatively short-term tests are possible.

The integration of a MarM-247 heater head onto the ASC-E2 design, and into the ASRG brought significant challenges in the fabrication process. The nickel heat collector that was used with a $650{ }^{\circ} \mathrm{C}$ heater head design did not have sufficient strength for the launch loads or potentially for the axial preload over the 17-year design life. The substitution of a stronger material inherently compromises the thermal conductivity compared to pure nickel. With the desire to potentially operate up to $850{ }^{\circ} \mathrm{C}$, diffusion bonding replaced braze joints making the heater head 
assembly process more complex. Furthermore, the steps necessary to perform precision machining of the thin wall, MarM-247 heater head, and to achieve the cleanliness needed for diffusion bonding needed to be verified to ensure that none of the salient material properties had been changed.

These efforts reduce risk and enhance reliability by determining and characterizing sources of variability, finding methods to minimize the variability, and ensuring that a repeatable, well-understood component or assembly is produced.

\section{Structures}

The primary focus of GRC structural analysis has been the life of the heater head. This has been performed in the past after a heater head design has been completed and used to assess the margins in the design. At times, the life analysis might find a location or feature that had negative margin, and the design would require slight adjustments to produce positive margins throughout. The technique generally involves steps of 1) materials testing, 2) preliminary creep analysis, 3) preliminary elastic analysis, 4) detailed elastic-plastic analysis, and finally 5) life assessment. Technical standards for spaceflight hardware recommend a guideline of a minimum service life safety factor of 4 on creep life for well-characterized materials. The ASRG "spec" MarM-247 material for use on the ASC-E2 convertor, however, is not a well-characterized material. Therefore, the GRC structural engineers developed a set of design guidelines that, if followed, should result in a heater head with a high probability of meeting the life requirements and remaining in secondary creep throughout the 17-year design life. The proposed guidelines called for the heater head analysis to show positive margins relative to limits set for through-thickness average creep strain, limits for local creep strain, and the time at the onset of tertiary creep. The proposed limits called for 1)the calculated throughthickness average creep strain at any location must be equal to or less than the average creep strain at the onset of tertiary creep based on GRC test data, 2) calculated peak local creep strains must be equal to or less than $70 \%$ of the minimum observed creep strains to failure from any GRC test data, and 3) the calculated average time to the onset of tertiary creep at every through-thickness location must be equal to or greater than the lower of $70 \%$ of the time to rupture, or the time to onset of tertiary creep based on the GRC test data. The first criterion results in the limiting heater head creep strains under "relaxed stresses" to the secondary creep regime, and therefore, restricts the strains to the more predictable and linear portion of creep behavior. The second criterion allows localized stresses to relax and redistribute by creep, while retaining margin on the local creep strain relative to the average strain through the wall. The third criterion provides assurance that the heater head will remain in secondary creep, with the limit expressed in terms of time rather than in terms of allowable strain. This technique proved to be difficult with the MarM-247 heater head of the ASC-E2 design, due in part to the limited creep database with material of appropriate thickness and the residual stresses from manufacturing combined with the stresses created as by temperature gradients that result during operation. Previous analyses of Inconel 718 heater heads for this project were conducted with just the heater head shell, not considering the effect of the heat collector. The present analysis for the ASC-E2 heater head made from MarM-247, as it would operate in an ASRG, is more complete as it does include all of the internal and external heat exchangers, residual stresses from manufacturing, and the preload applied from system integration. ${ }^{13,14}$

Structural benchmark testing of heater head shells will be conducted to validate analytical models and to complement the uniaxial creep testing of MarM-247. ${ }^{15}$ During benchmark testing, the heater head will experience multi-axial stresses similar to what exists during operation in a generator. Diametral extensometers and a pair of movable laser micrometers measure creep during the test. Figure 4 shows one of the two GRC test stations. The test station is able to pressurize the heater head to pressures above the nominal operating point of the ASC-E2 to accelerate creep.

A "cascade" testing technique is used in which the tapered section of the wall, which results in higher stressed areas, are operated at temperatures higher than they will experience in nominal operation. This results in creep that

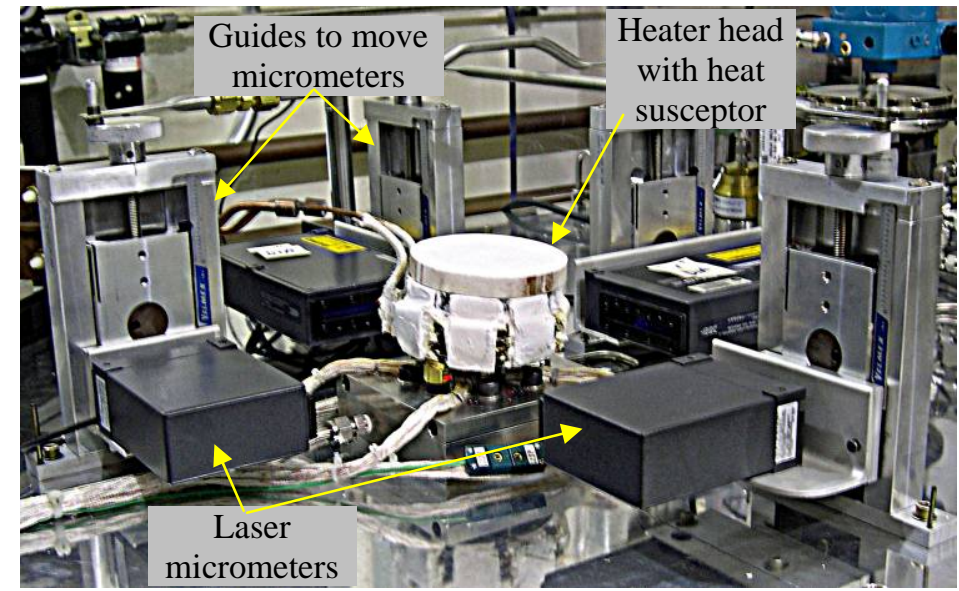

Figure 4. Heater head structural benchmark test. One of two test stations for heater head structural benchmark testing showing the laser micrometers that can be repositioned, and a heater head in the center with insulated heat susceptor. 
is accelerated by temperature. Creep as a function of axial position on the heated, tapered wall provides data over a range of acceleration factors as the stress varies along the wall.

This tasks mitigates risk and enhances reliability by characterizing and verifying life of the sole component that may change during a mission. Conservative design practices have been proposed to further mitigate risk.

\section{E. Advanced Analysis}

The techniques necessary for creating three-dimensional Computational Fluid Dynamic (CFD) models of complete Stirling convertors have been developed at GRC. ${ }^{16}$ This has often been proposed as a method for shortening the time it takes to develop a Stirling convertor as modifications can be made more quickly to the model and analysis performed than many hardware modifications. When applied properly, this should ultimately result in cost savings. Similarly, the analysis could aid in optimizing the performance of a convertor by varying parameters that result in losses, and the power or efficiency can be optimized. The analytical support for the ASC-E2 did not seek to improve efficiency; rather, it concentrated on the gas bearing system to determine if relatively minor changes in the hardware dimensions might result in a significant increase in margin. The margin in this case is the resistance to any contact of the moving components. To simplify the analysis, the model included the displacer, the piston, and the cylinder in the ASC-E configuration. This model defined the gas bearing system operating under prescribed cyclic pressure variations and axial motions. This baseline model allowed the calculation of all of the flow rates and forces acting on the components over the cycle. This baseline case represents what might occur in space with the piston and displacer operating with zero eccentricity. The desire for a robust bearing system is to have increased margin during times of lateral loads, such as during launch.

The model allowed the calculation of restoring forces over the cycle after an eccentricity was imposed. The first change from the baseline was a modification to the drain path for gas to flow from the gas bearing system back to mean pressure of the bounce space. This modification resulted in an anticipated $40 \%$ increase in capacity for the displacer gas bearings. Some of the key dimensions of the gas bearing system were then varied parametrically to try to find an optimal configuration. The location of the gas bearing pads were also moved parametrically to try to find optimal locations. The results indicated that the gas bearing design was near optimal. However, a significant improvement in the bearing capability was found with a change in the shape of the bearing pad, however, the proposed shape brought manufacturing complexity. This option may be pursued in the future as trades are performed looking at the more complex manufacturing techniques and increased load carrying capability.

Further studies considered fault scenarios in which flow passages were assumed to be blocked. This analysis showed that while the stiffness of the gas bearing system was reduced, there remained a restoring force for noncontacting operation.

This task mitigates risk in long-term operation by increasing margin in the gas bearing system and evaluating fault tolerance.

\section{F. Organic Materials}

Organic materials in the ASC designs are used for electrical insulation, potting compounds, structural bonding, and as surfaces for close clearance seals where there might be momentary contact of moving parts. The ASC-E2 will have 11 types of organics with most residing in the area of the linear alternator. ${ }^{17}$ Organics characteristics being evaluated at GRC include outgassing, magnet bond strength, thermal stability, long-term aging, and radiation tolerance. The epoxies are being evaluated through long-term aging tests at near-nominal operating conditions, and through shorter term accelerated aging tests. The objectives of these tests include detecting any sign of premature degradation, and establishing lifetime performance predictions. The properties that are evaluated for change over time include the mass, thermal-physical-chemical properties, bond strength, and fatigue strength. After nine months of the long-term simulated aging test of the epoxies, there have been no signs of thermal degradation. Some of the samples in the long-term aging test will be aged for 5-10 years. The accelerated aging test has not started as the conditions that will be used are currently under investigation. Samples are being tested for 15 days at seven different temperatures to determine the maximum temperature for the accelerated aging test that does not change the fundamental aging mechanism.

Another aspect to be considered is the radiation hardness of the organics. This effort will verify that radiation does not impact the performance of the organic materials. A preliminary assessment through the literature provided some useful information, however it was not sufficient. Irradiation testing is being planned in collaboration with the DOE labs and the University of Florida under a joint effort involving the NASA Fission Surface Power project. The test will evaluate the most susceptible organics, namely the epoxies, a small internal o-ring, the surface coating on the moving components, and the electrical insulators. The test as planned will use gamma exposure in an inert environment with controlled temperatures. A specimen holder has been designed that results in specimens exposed 
to varying dosages in a single test based on their locations relative to the gamma source. A follow-on test is currently in the planning stage in which a resonant component similar to the piston and linear alternator will be operated while being exposed to the gamma source. The operating characteristics of the resonating piston will be able to be observed as the test article is irradiated.

This task mitigates risk by characterizing the material that may degrade over time, or could be effected by the radiation environment. Tests are being conducted to simulate may of the mechanism that could cause aging.

\section{G. Permanent Magnets}

GRC originally developed methods for long-life testing of candidate magnets for the SP-100 project. These methods have been further refined and are now being applied to the ASC project. ${ }^{18}$ Aging tests are performed on 1$\mathrm{cm}$ cube samples as a means to characterize the performance of the magnet material selected for the ASC-E. The temperatures of the ASC require the use of high performance neodymium-iron-boron (NdFeB) magnets. The tests are intended to verify that the magnets provide margin under all operating conditions. The remanence, intrinsic coercivity and magnetization of each of the sample magnets were measured over the temperature range of 20 to 140 ${ }^{\circ} \mathrm{C}$. These tests verify the performance of the magnet material against vendor specifications and check for consistency of the characteristics. If magnets of a particular type or from a vendor were found to vary excessively, they were eliminated from consideration.

Following characterization, the selected magnet grade underwent a 200-hour, short-term aging test, with the samples exposed to a field of $-5.0 \mathrm{kOe}$ at $150{ }^{\circ} \mathrm{C}$. These conditions exceed the expected operating conditions of the convertor and to accentuate any possible aging effects. Magnet grades need to demonstrate minimal to no change in properties during the short-term test and then become candidates for a long-term aging test. The long-term test exposes the magnets to a $-9.0 \mathrm{kOe}$ demagnetizing field at $130{ }^{\circ} \mathrm{C}$ in a helium environment. These values exceed the expected conditions expected in the ASRG system to verify the margin. The long-term aging test will run for a total of 18,000 hours. The samples reached 12,000 hours as of June 2008.

In anticipation of potential higher-temperature operation, as would exist at some locations on the lunar surface, a long-term magnet aging test of five Samarium-Cobalt (SmCo) magnet samples from two different vendors has been initiated on a second test rig. In this test, the magnets are maintained at a temperature of $250{ }^{\circ} \mathrm{C}$ in a helium environment with constant exposure to an external demagnetization field of -9 kOe. The magnets have now been under test for over 7,000 hours of the planned 18,000-hour test duration.

This task mitigates risk by providing verification of the long life capability of permanent magnets at conditions in excess of the intended application. Techniques have been developed for screening through shorter term tests. The testing techniques also verify that there is margin in the capability of the magnets.

\section{Future Efforts}

The earlier sections of this report contained a description of many of the future efforts. Creep testing of the selected MarM-247 material will begin once the material samples have been prepared. Structural benchmark testing of heater heads will also commence when samples are ready. Other than the long-term aging tests or extended operation tests, all of the tasks focus on enhancing reliability with clearly defined products in support of the ASC development.

Convertor testing tasks may undergo the most significant change. As mentioned earlier, LMSSC has completed their testing of the ASRG-EU. The generator will begin extended operation as an integrated system in a test facility at GRC in 2008. The facility has had additional failsafe features included beyond those used in the past. In addition to a uninterruptible power supply, a backup generator is being installed to protect against loss of power to the test stand. Also, a system has been designed that will allow natural convection to cool the generator in the event that the facility chillers fail.

The ASC-Es supplied to LMSSC for use in the ASRG-EU included a spare convertor. The generator incorporates ASC-Es \#2 and \#3, while ASC-E \#1has been in storage as a spare. Since that time, an additional ASCE, designated as \#4 has been assembled. The two spare ASC-Es will be installed on a test stand next to the ASRG as shown in Figure 5. The housing for the ASC-E \#1 and \#4 convertors has been designed to representative of the size and general shape of the ASRG. These will also go on extended operation with the failsafe and backup power in place. A heat flux sensor developed for the ASC project will first be tested on ASC-E \#1 and \#4. Figure 6 shows the sensor. The purpose of the heat flux sensor is to more accurately measure the heat that goes into the Stirling convertor compared to using energy balances to account for insulation losses.

Techniques for measuring acoustics of operating Stirling convertors are also under development at GRC. The goal of the effort is to detect the signature of a properly operating convertor, and that of improper operation. If 
successful, this technique will be used verify non-contacting operation of the internal components. In tests on a previous design, it appeared that the system could distinguish between proper operation, contact of a surface coated with the organic surface finish, and metal-to-metal contact.

The ASC-E design is presently transitioning into the ASC-E2, which will later become the ASC-E3. The intent is to minimize design changes through this progression, with only refinements for manufacturing, quality, and process control. All of these efforts seek to minimize risk and enhance reliability. As the project is envisioned, the ASC will then transition to formal flight development as the qualification unit would soon follow.

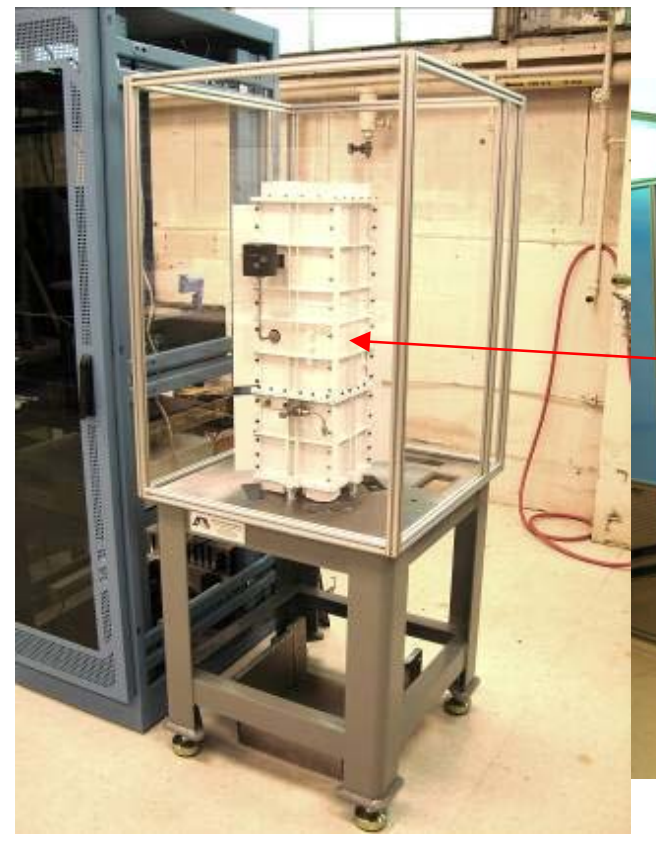

a) ASRG EU in enclosure on test stand.

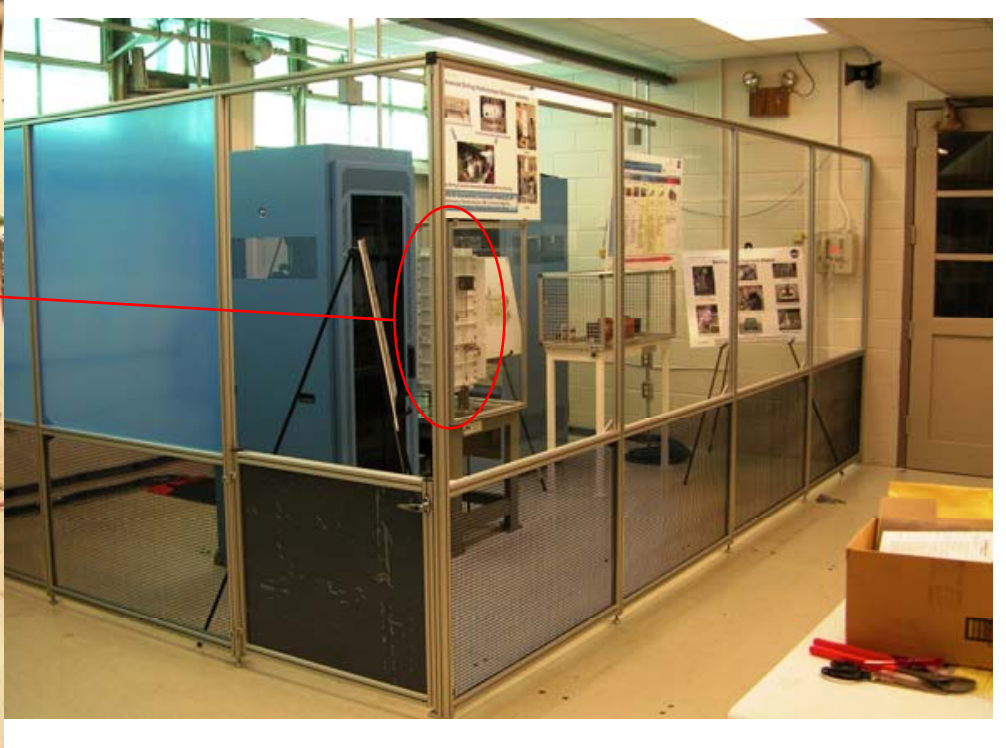

b) ASRG EU and ASC-E \#1 \& \#4 test facility.

Figure 5. Facility being prepared for ASRG-EU and spare ASC-E convertors. The facility will house the ASRG-EU on and the spare pair of ASC-Es. All support systems have been designed to allow failsafe operation.

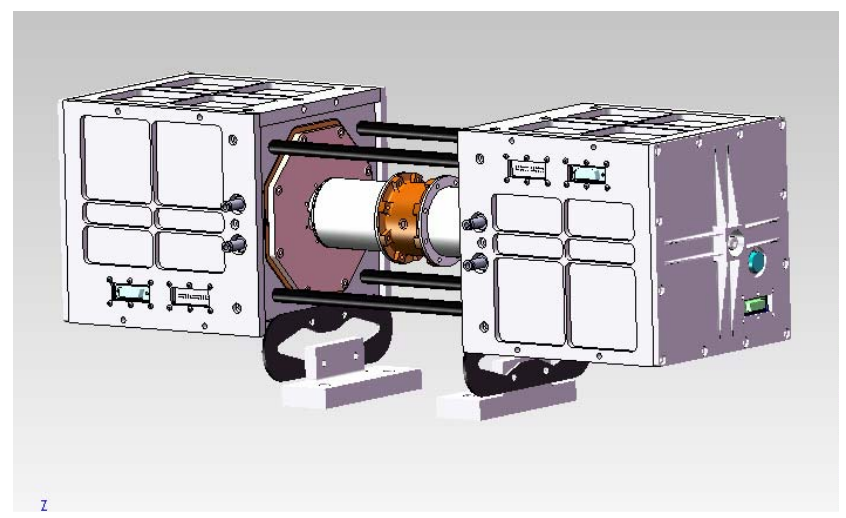

a) Test configuration for the spare ASC-E convertors.

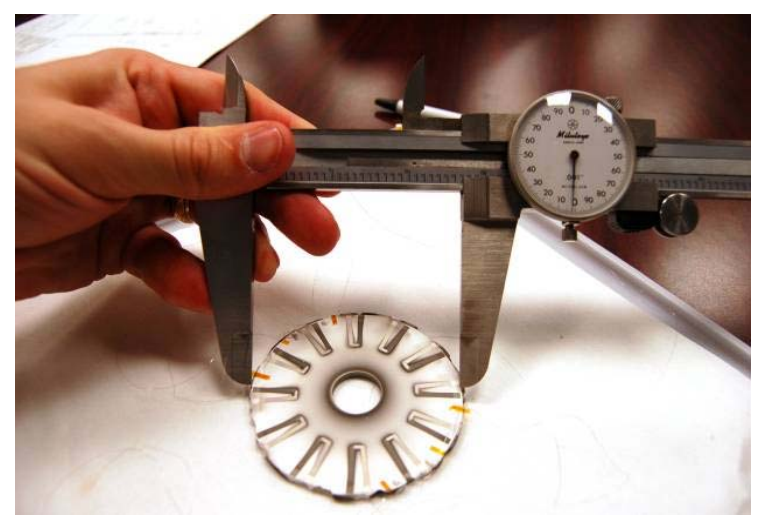

b) Heat flux sensor being developed for ASC-E testing.

Figure 6. Test hardware for the ASC-E \#1 and \#4 convertors. The test housing for the spare ASC-Es will emulate the ASRG in size and appearance. The heat flux sensor will be used in the ASC-E \#1 and \#4 test stand to directly measure heat input to the heater head. 


\section{Conclusion}

The efforts described in this paper do not seek to increase performance or reduce the mass of the ASC convertors, rather, they target risk mitigation wherever possible and enhanced reliability of the Stirling convertor. The efforts covered in this paper include reliability, convertor testing, materials, structures, advanced analysis, organics, and magnets. These tasks are often work in areas where the Stirling convertor application is unique and industry standard data in the open literature is not adequate. All of the tasks are on a schedule intended to support the transition of the ASC to a potential flight status.

\section{Acknowledgments}

This work is funded through the NASA Science Mission Directorate. Any opinions, findings, and conclusions or recommendations expressed in this article are those of the authors and do not necessarily reflect the views of the National Aeronautics and Space Administration.

\section{References}

${ }^{1}$ Brown, A. T., “Space Power Demonstrator Engine - Phase 1 Final Report”, NASA CR-179555, 1987.

${ }^{2}$ Dochat, G., “SPDE/SPRE Final Summary Report”, NASA CR-187086, 1993.

${ }^{3}$ Dhar, M., "Stirling Space Engine Program, Volume 1 - Final Report”, NASA CR-1999-209164, 1999.

${ }^{4}$ Bents, D.J., "Preliminary Assessment of Rover Power Systems for the Mars Rover Sample Return Mission,” Proceedings of the International Conference on Space Power, Cleveland, OH, 1989, NASA TM-102003.

${ }^{5}$ Bents, D.J., Schreiber, J.G. Withrow, C.A., McKissock, B.I., and Schmitz, P.C., "Design of Small Stirling Dynamic Isotope Power System for Robotic Space Missions," Proceedings of the $10^{\text {th }}$ Symposium on Space Nuclear Power and Propulsion, Albuquerque, NM, 1993, pp. 213-221, NASA TM-105919.

${ }^{6}$ Schmitz, P.C., Kenny, B.H., and Fulmer, C., "Preliminary Design of a Mobile Lunar Power Supply,” NASA TM-104471, 1991.

${ }^{7}$ Ross, B.A., “Multi-Hundred Watt Stirling Technology Demonstrator for Space Power”, Small Business Innovative Research final report, contract NAS3-26722, 1993.

${ }^{8}$ Shaltens, R.K., and Wong, W.A., “Advanced Stirling Technology Development at NASA Glenn Research Center”, NASA TM-2007-214930, 2007.

${ }^{9}$ Wood,J.G., and Lane, N., "Development of the Sunpower 35 We Free-Piston Stirling Convertor”, Proceedings of the Space Technology and Applications International Forum, Albuquerque, NM, 2005, pp 682-687.

${ }^{10}$ Chan, J., Wood, J.G., and Schreiber, J.G., "Development of Advanced Stirling Radioisotope Generator for Space Exploration”, NASA TM-2007-214806, 2007.

${ }^{11}$ Chamis, C.C., "Probabilistic Structural Analysis Methods for Space Propulsion System Components", Probabilistic Engineering Mechanics, vol. 2, no.2, pp 100-110, 1987.

${ }^{12}$ Ha, C.T., Fernandez, R., Cornford, S.L., and Feather, M.S., “Advanced Stirling Radioisotope Generator: Design Process Reliability Analysis Impacts, and Extended Operation Tests”, Proceedings of the Space Technology and Applications International Forum, Albuquerque, NM, 2008.

${ }^{13}$ Shah, A., Korovaichuk, I., Krause, D.L., and Kalluri, S., “Advanced Stirling Convertor Heater Head Durability and Reliability Quantification”, 6 ${ }^{\text {th }}$ International Energy Conversion Engineering Conference, AIAA-2008-5772, 2008.

${ }^{14}$ Aziz, A., Kalluri, S., and Krause, D.L., "Long Term Creep Behavior of Materials Used for Stirling Convertors under InPlane Biaxial Loading Conditions”, $6^{\text {th }}$ International Energy Conversion Engineering Conference, AIAA-2008-5773, 2008.

${ }^{15}$ Krause, D.L., Kalluri, S., Bowman, R.R., and Shah, A.R., "Structural Benchmark Creep Testing for the Advanced Stirling Convertor Heater Head”, $6^{\text {th }}$ International Energy Conversion Engineering Conference, AIAA-2008-5774, 2008.

${ }^{16}$ Dyson, R.W., Geng, S.M., and Tew, R.C., "Towards Fully Three-Dimensional Virtual Stirling Convertors for Multiphysics Analysis and Optimization”, $4^{\text {th }}$ International Energy Conversion Engineering Conference, AIAA-2006-4002, 2006.

${ }^{17}$ Shin, E.E., Scheiman, D., Cybulski, M., Quade, D., Inghram, L., and Burke, C., "Validation of Organics for Advanced Stirling Convertor (ASC)", Proceedings of the Space Technology and Applications International Forum, Albuquerque, NM, 2008.

${ }^{18}$ Geng, S.M., Schwarze, G.E., and Niedra, J.M., “Overview of NASA Magnet and Linear Alternator Research Efforts”, NASA TM-2005-213411, 2005. 